\title{
Dynamic Characteristics of a Misaligned Rigid Rotor System with Flexible Supports
}

\author{
Meiling Wang, ${ }^{1,2}$ Baogang Wen, ${ }^{3}$ Qingkai Han, ${ }^{4}$ Yibo Sun, ${ }^{1}$ and Changxin $\mathbf{Y u}^{2}$ \\ ${ }^{1}$ College of Locomotive and Rolling Stock Engineering, Dalian Jiaotong University, Dalian 116028, China \\ ${ }^{2}$ Wafangdian Bearing Group Corp, Wafangdian 116300, China \\ ${ }^{3}$ School of Mechanical Engineering and Automation, Dalian Polytechnic University, Dalian 116034, China \\ ${ }^{4}$ School of Mechanical Engineering and Automation, Northeastern University, Shenyang 110819, China \\ Correspondence should be addressed to Baogang Wen; wbg_dlut@163.com
}

Received 30 August 2020; Revised 4 February 2021; Accepted 8 March 2021; Published 16 April 2021

Academic Editor: Dejan Gjorgjevikj

Copyright @ 2021 Meiling Wang et al. This is an open access article distributed under the Creative Commons Attribution License, which permits unrestricted use, distribution, and reproduction in any medium, provided the original work is properly cited.

\begin{abstract}
A misaligned rigid rotor system with flexible supports differing from the traditional flexible rotor system, which refers to its practical rotating center line determined by supports offset from the theoretical one, often suffers support structure damage risk. In the present work, the dynamic characteristics of a misaligned rigid rotor system with flexible squirrel cage supports are focused, and the vibrations and the stress of its support structures under different misaligned offsets are investigated with experimental and simulated analysis. The finite element model for a rigid rotor system with flexible supports in a scaled test rig is established, and its strain energy distribution is analyzed to find that the first two modes of the system are referred to rigid-body modes and the strain energy is mainly distributed on the squirrel cage supports. Based on the analysis results, a rigid-flexible coupling dynamic model is proposed through a data exchange between ADAMS and ANSYS and validated by measurements. The misaligned conditions are focused on, and the influences of misalignment on the vibrations of the rigid rotor system and the reaction force and stress of its support structures are investigated analytically and experimentally. The results from simulation agree very well with the measurements and reveal that the static stress of squirrel cage increases just about proportionally with misalignment levels, but the vibration displacement amplitudes and stress amplitudes show very little change. The more serious the misaligned condition, the higher the static stress of the squirrel cage. Because misalignment will bring out the additional reaction forces in the misaligned direction, it will further result in higher stress and even more serious damage risk for the flexible supports than other parts in the rigid rotor system.
\end{abstract}

\section{Introduction}

Misalignment in the rotor system is widely present because of improper assembly and thermal distortion of supports etc. and will induce abnormal vibration and damage of the rotor system over a long period of time, even resulting in premature support structure or coupling failures [1]. Thus, it is very important to accurately predict the dynamic characteristics of a misaligned rotor system in the early stage.

Presently, many analytical methods are in application for the rotor dynamic analysis, but can be commonly subdivided into the lumped-parameter method- Myklestadt method, transfer matrix method, and finite element method [2]. The former two methods are efficient solutions only for 1D inline systems, and the finite element method is well recognized as one of the most powerful computational methods to deal with various complex problems beyond rotor dynamic analysis, such as nanobeam systems $[3,4]$. In [5], the rotor and casing systems are modeled using the finite element method and supports are modeled as lumped-parameter models to analyze the vibration behaviors of a rotorcasing system in an aeroengine. Zuo and Wang [6] analyzed the dual rotor system in an aeroengine by modelling casing, bearings, and counter-rotating dual rotors with the $3 \mathrm{D}$ finite element method. However, the finite element method requires a huge number of degrees of freedom (DOFs) to improve its accuracy, especially when a rotor system has a complex structure and is operating at a relatively high speed.

As to misalignment studies, a majority of the recent ones have mainly analyzed coupling misalignment and discussed 
the effects of its structure and type on the vibration of connected rotor system. $\mathrm{Xu}$ and Marangoni [7, 8] derived reaction torques of misaligned hook coupling, proposed the corresponding experiment, and showed that the vibration responses due to coupling misalignment mainly occur at the even integer multiples of the rotating speed. Sekhar and Prabhu [9] introduced reaction forces and moments due to flexible coupling misalignment in the model, and the numerical and experimental work evaluated the $2 \mathrm{x}$ vibration response as to be an important characteristic feature of misalignment. Lee and Lee [10] derived a dynamic model for a misaligned rotor system by treating the reaction loads and deformations at the bearing and coupling elements as the misalignment effect. Hussain and Redmond [11, 12] presented a shaft misalignment model supported by three bearings, and the numerical results showed that only parallel misalignment may produce system a dynamic response while angular misalignment may generate purely static forces and displacements by theoretical analysis. The authors have dealt with rigid coupling misalignment of a hyperstatic shaft-line equipped with journal bearings in [13], and their simulation results showed that superharmonic components were the most remarkable effects of rigid coupling misalignment. Feng et al. [14] modeled a quill-shaft coupling-rotor-bearing system considering the stiffness of the quill-shaft coupling by using the finite element method. Yi et al. [15] presented a simplified model of misaligned-installing matched bearings and derived the nonlinear restoring force due to parallel misalignment arising in practical installing.

Additionally, the flexible supports have a significant influence on the dynamic behavior of rotor system $[16,17]$. The rigid rotor system with flexible supports, widely used in practical applications such as the rotor system of an aeroengine, has the shaft much stiffer than the supports and hardly with deformation in the working range, the motion patterns of which are often different from those of the traditional flexible rotor system in many rotating machinery [18]. Messager and Pyrz [19] investigated a simple model of a rigid rotor and discussed the discrete optimizations in balancing. Zapomèl et al. [20] investigated the dynamical behavior of a rigid flexibly supported rotor loaded by its unbalance and equipped with two short magnetorheological squeeze film dampers and analyzed their steady-state response. Liu and Shao $[21,22]$ proposed a dynamic model to analyze the influences of localized defect (LOD) sizes on the vibration characteristics of the rigid bearing system, considering the effect of housing support stiffness. Bekir and Omer [23] investigated the static bending response of single-walled carbon nanotubes (SWCNTs) embedded in an elastic medium by introducing the Winkler elastic foundation model for the flexible supports.

As to the misaligned rigid rotor system with flexible supports, misalignment is frequently observed and often brings out damage risks, especially for the support structures $[22,23]$, but there is no clear-cut picture for its dynamic characteristics at present, especially the effects of misalignment on the characteristics of flexible supports.
In this paper, based on the strain energy distribution analysis of a scaled test rig by the finite element method, a rigidflexible coupling dynamic model is established through a data exchange between ADAMS and ANSYS considering the flexibility of the supports and misaligned conditions. A validation study is performed for the present model with the obtained data from measurements, and a good agreement is observed. Then, vibrations of the misaligned rigid rotor system and the stress of its support structures under different misalignment levels are investigated by simulation and measurement.

\section{Modeling the Misaligned Rigid Rotor System with Flexible Supports}

2.1. Test Rig. It is often extremely hard to measure on original systems with complex structures in practice, so it is of great significance to set up a scaled test rig. One scaled test rig for a rigid rotor system with flexible supports in high rotating machinery is designed satisfying geometric and dynamic similarity principles proposed in [24], as shown in Figure 1, in which one disc is located in the middle of shaft and the two supports on the two sides of shaft include bearings, bearing houses, squirrel cages, and support houses. The shaft and squirrel cages are made by $40 \mathrm{Cr}$ steel, and the main geometrical and material parameters of the test rig are listed in Tables 1 and 2 [16]. Remarkably, the stiffness of the flexible supports can be easily changed by altering the structures of the squirrel cage, and their stress and elastic deformations also be conveniently measured.

The rotating speed of the shaft can be continuously changed from 0 to $6000 \mathrm{rpm}$. Four eddy probes are mounted near the disc and supports to measure the shaft displacements in the horizontal and vertical directions, respectively. The strain gauges are stuck on the squirrel cage to measure its stain in different operation conditions.

2.2. Finite Element Model of the System and Its Energy Distribution Analysis. The finite element (FE) model for the abovementioned test rig is established by assembling components, as shown in Figure 2, in which the disc and two supports are located at the 6\#, 2\#, and 10\# nodes, respectively. The rotating beam element, mass element, and spring-damper element are adopted in the FE model to describe the shaft, disc, and the flexible supports, respectively, and the corresponding element characteristics are described as follows. Also, the adopted material is the $40 \mathrm{Cr}$ steel, and the parameters of the beam elements are listed in Table 3.

The governing equations of the rotor system or the FE model of it is established as

$$
\mathbf{M} \ddot{q}+(\mathbf{C}+\Omega \mathbf{G}) \dot{q}+\mathbf{K q}=\mathbf{Q},
$$

where, $\mathbf{q}, \dot{q}, \ddot{q}$ and of size $1 \times 66$ are the displacement vector and its corresponding velocity, acceleration vector, and the excitation force vectors, respectively. The mass, damping, gyroscopic, and stiffness matrices $\mathbf{M}, \mathbf{C}, \mathbf{G}$, and $\mathbf{K}$ of the rotor system are of size $66 \times 66$. The generalized displacements of all nodes with 66 -DOF can be written as 


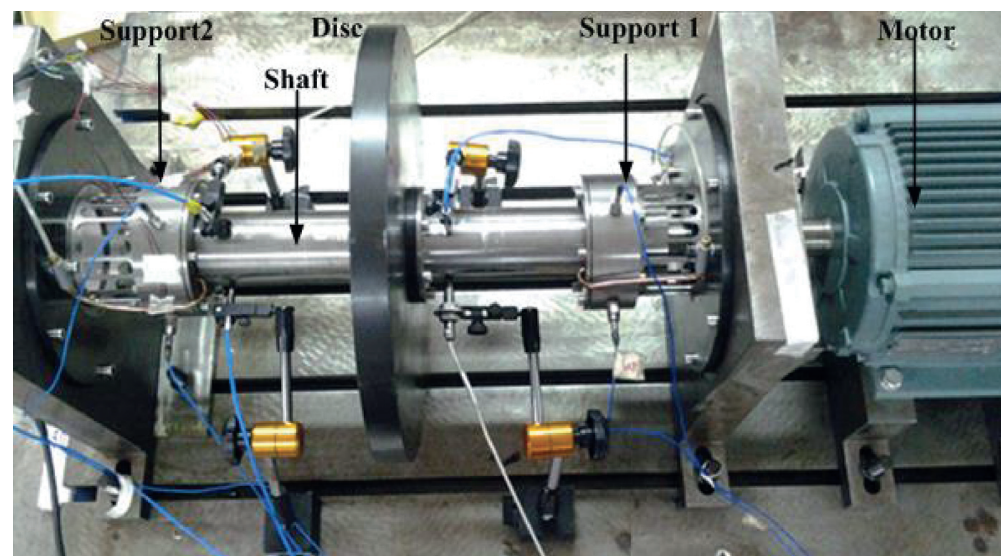

(a)

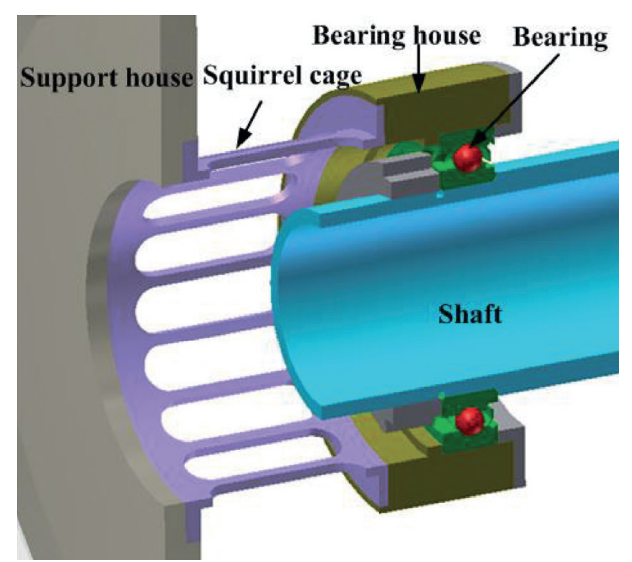

(b)

Figure 1: Scaled test rig. (a) Photo of the scaled test rig. (b) Cross-view of the support structure.

TABle 1: Parameters of the scaled test rig.

\begin{tabular}{lc}
\hline Parameters & Value \\
\hline Shaft length & $0.498 \mathrm{~m}$ \\
Shaft inner/outer diameter & $0.056 / 0.07 \mathrm{~m}$ \\
Disc diameter/thickness & $0.41 / 0.03 \mathrm{~m}$ \\
Elastic modulus & $2.09 \times 10^{11} \mathrm{~Pa}$ \\
Poisson's ratio & 0.295 \\
Material density & $7.87 \times 10^{3} \mathrm{~kg} / \mathrm{m}^{3}$ \\
\hline
\end{tabular}

TABle 2: Parameters of the squirrel cage.

Parameters Value

Number of cage rib- $n$

Length of cage rib- $l$

Cross-sectional width of cage rib- $b$

$0.0506 \mathrm{~m}$

Cross-sectional height of cage rib- $h$

$0.0043 \mathrm{~m}$ $0.003 \mathrm{~m}$

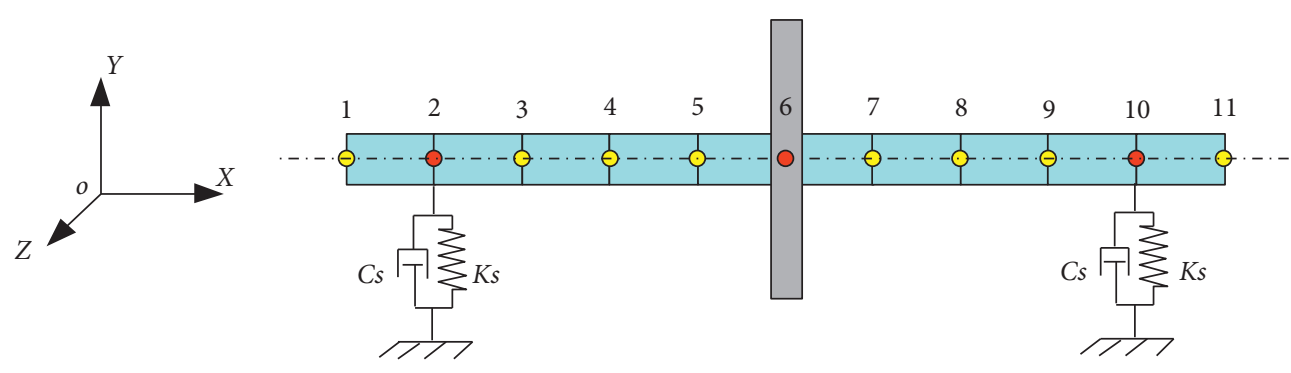

Figure 2: FE model of the rotor system.

TABle 3: Parameters of beam elements of the FE model.

\begin{tabular}{lcccc}
\hline No. of elements & No. of nodes & Inner diameter $(\mathrm{m})$ & Outer diameter $(\mathrm{m})$ & Length $(\mathrm{m})$ \\
\hline 1 & $1-2$ & 0.056 & 0.070 & 0.070 \\
2 & $2-3$ & 0.056 & 0.070 & 0.049 \\
3 & $3-4$ & 0.056 & 0.070 & 0.049 \\
4 & $4-5$ & 0.056 & 0.070 & 0.049 \\
5 & $5-6$ & 0.056 & 0.070 & 0.0515 \\
6 & $6-7$ & 0.056 & 0.070 & 0.0515 \\
7 & $7-8$ & 0.056 & 0.070 & 0.0515 \\
8 & $8-9$ & 0.056 & 0.070 & 0.048 \\
9 & $9-10$ & 0.056 & 0.070 & 0.048 \\
10 & $10-11$ & 0.056 & & 0.049 \\
\hline
\end{tabular}


$\mathbf{q}=\left\{\begin{array}{lllllllllllll}x_{1} & y_{1} & z_{1} & \theta_{x 1} & \theta_{y 1} & \theta_{z 1} & \ldots & x_{11} & y_{11} & z_{11} & \theta_{x 11} & \theta_{y 11} & \theta_{z 11}\end{array}\right\}^{T}$,

where $x_{\mathrm{i}}, y_{\mathrm{i}}, z_{\mathrm{i}}, \theta_{x i}, \theta_{y i}, \theta_{z i}(i=1-11)$ are the transverse displacements and rotation angles of the $i$ th node in the three coordinate axes.

2.2.1. Element Characteristics in the FE Model. The rotating beam element chosen in the model is defined as one elastic beam with distributed mass, two nodes, and 12 degrees of freedom, as shown in Figure 3. So, the generalized displacement of the rotating beam element can be written as

$$
\mathbf{u}_{\mathbf{e}}=\left\{\begin{array}{llllllllllll}
x_{i} & y_{i} & z_{i} & \theta_{x i} & \theta_{y i} & \theta_{z i} & x_{j} & y_{j} & z_{j} & \theta_{x j} & \theta_{y j} & \theta_{z j}
\end{array}\right\}^{T},
$$

where $i$ and $j$ represent the two nodes of the element. Also, $x$, $y, z, \theta_{x}, \theta_{y}$, and $\theta_{z}$ denote the translation and rotation freedoms in $x-, y-, z$ - direction, respectively.

The dynamic equation of the beam element can be described as

$$
\mathbf{M}_{\mathrm{e}} \ddot{u}_{\mathrm{e}}+\left(\mathbf{C}_{\mathrm{e}}+\Omega \mathbf{G}_{\mathrm{e}}\right) \dot{u}_{\mathrm{e}}+\mathbf{K}_{\mathrm{e}} \mathbf{u}_{\mathrm{e}}=\mathrm{F}_{\mathrm{e}},
$$

where $\Omega$ is the rotating speed around the $x$-axis; $\boldsymbol{F}_{\mathrm{e}}$ is the force vector of the beam element; $\boldsymbol{K}_{\mathrm{e}}, \boldsymbol{G}_{\mathrm{e}}$, and $\boldsymbol{M}_{\mathrm{e}}$ are the

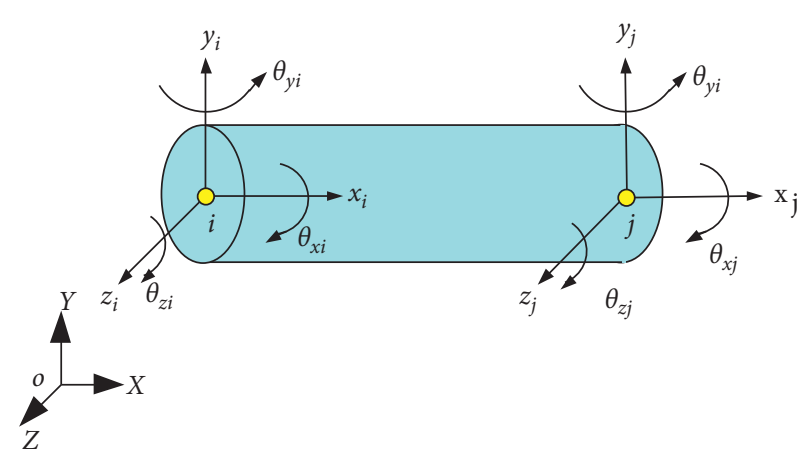

Figure 3: Rotating beam element.

stiffness matrix, gyroscopic matrix, and mass matrix, respectively [2]. Also, $\boldsymbol{C}_{\mathrm{e}}$ can be defined as Rayleigh damping and described as

$$
\mathbf{C}_{\mathbf{e}}=\alpha \cdot \mathbf{M}_{\mathbf{e}}+\beta \cdot \mathbf{K}_{\mathbf{e}},
$$

where $\alpha=2\left(\left(\xi_{2} / \omega_{2}\right)-\left(\xi_{1} / \omega_{1}\right)\right) /\left(\left(1 / \omega_{2}^{2}\right)-\left(1 / \omega_{1}^{2}\right)\right), \beta=2\left(\xi_{2}\right.$ $\left.\omega_{2}-\xi_{1} \omega_{1}\right) /\left(\omega_{2}^{2}-\omega_{1}^{2}\right)$. The coefficients $\xi_{1}$ and $\xi_{2}$ are constant damping coefficients, and $\omega_{1}, \omega_{2}$ are the first two natural frequencies $(\mathrm{rad} / \mathrm{s})$.

The stiffness, gyroscopic, and mass matrixes are as follows:

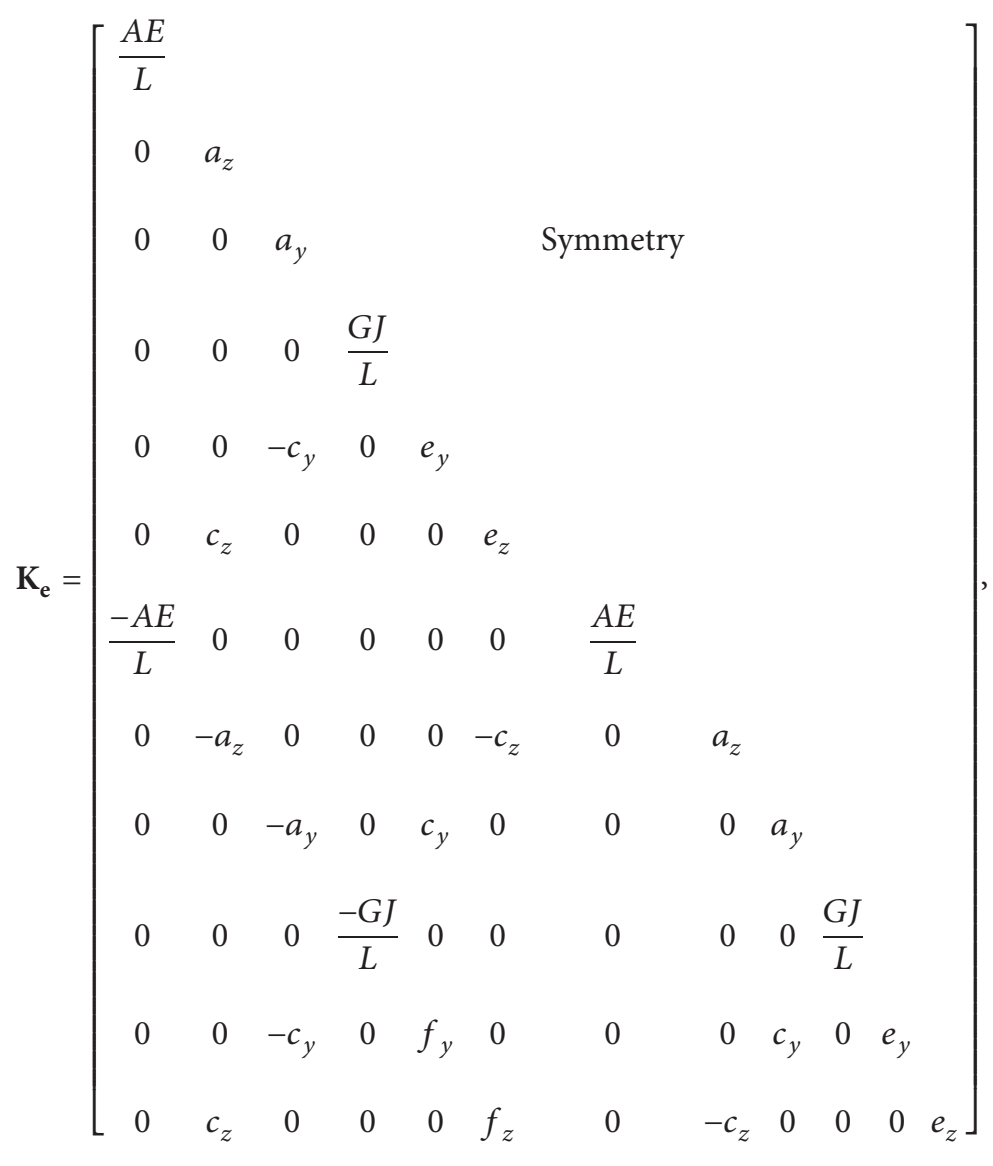




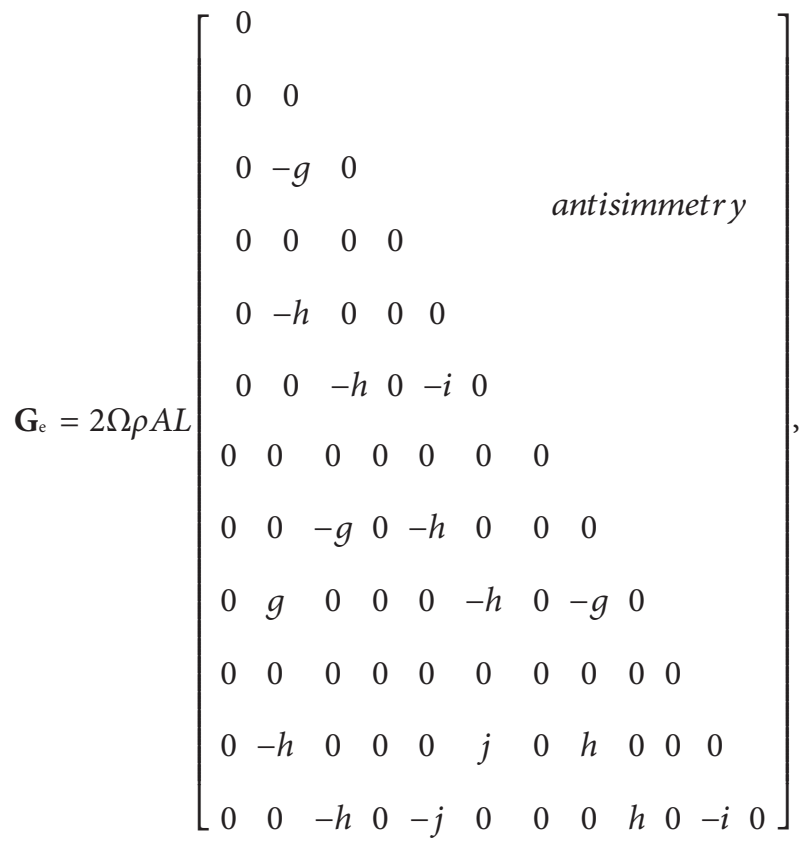

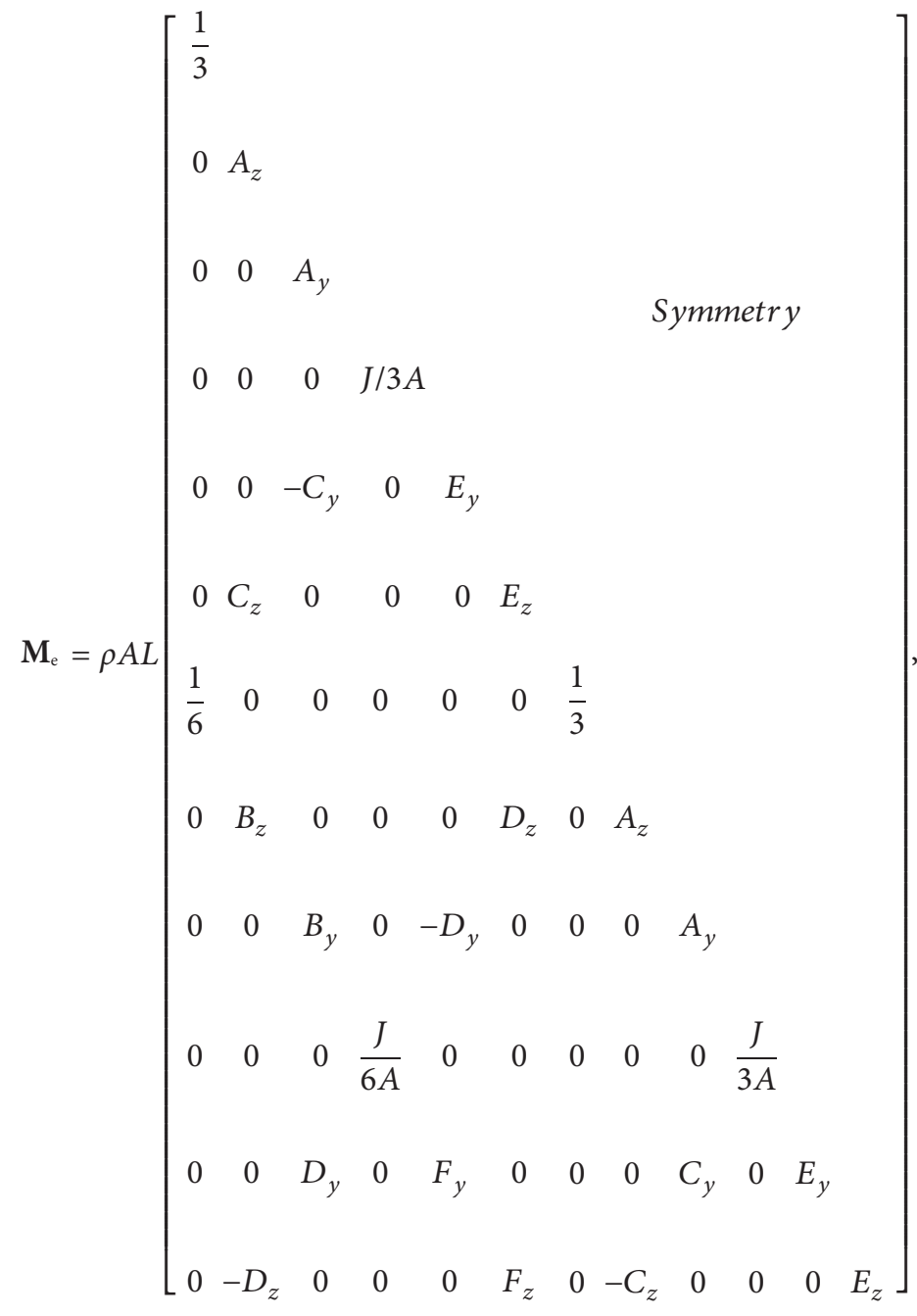




$$
\begin{aligned}
& a_{z}=\frac{12 E I_{z}}{L^{3}\left(1+\phi_{y}\right)}, \\
& a_{y}=\frac{12 E I_{y}}{L^{3}\left(1+\phi_{z}\right)} \text {, } \\
& c_{z}=\frac{6 E I_{z}}{L^{2}\left(1+\phi_{y}\right)} \text {, } \\
& c_{y}=\frac{6 E I_{y}}{L^{2}\left(1+\phi_{z}\right)}, \\
& e_{z}=\frac{\left(4+\phi_{y}\right) E I_{z}}{L\left(1+\phi_{y}\right)} \text {, } \\
& e_{y}=\frac{\left(4+\phi_{z}\right) E I_{y}}{L\left(1+\phi_{z}\right)} \\
& f_{z}=\frac{\left(2-\phi_{y}\right) E I_{z}}{L\left(1+\phi_{y}\right)}, \\
& f_{y}=\frac{\left(2-\phi_{z}\right) E I_{y}}{L\left(1+\phi_{z}\right)} \text {, } \\
& \phi_{y}=\frac{12 E I_{z}}{G A_{z}^{s} L^{2}} \text {, } \\
& \phi_{z}=\frac{12 E I_{y}}{G A_{y}^{s} L^{2}} \\
& I_{y}=I_{z}=I \text {, } \\
& A_{y}^{s}=A_{z}^{s}={ }_{A}^{s} \text {, } \\
& A^{s}=\frac{A}{2.0}, \\
& h=\frac{-(1 / 10-1 / 2 \phi) r^{2}}{L(1+\phi)^{2}}, \\
& i=\frac{\left(2 / 15+1 / 6 \phi+1 / 3 \phi^{2}\right) r^{2}}{(1+\phi)^{2}}, \\
& g=\frac{6 / 5 r^{2}}{L^{2}(1+\phi)^{2}} \\
& j=\frac{-\left(1 / 30+1 / 6 \phi-1 / 6 \phi^{2}\right) r^{2}}{(1+\phi)^{2}}, \\
& A_{z}=A_{y}=\frac{(13 / 35)+(7 / 10) \phi+(1 / 3) \phi^{2}+(6 / 5)(r / L)^{2}}{(1+\phi)^{2}} \text {, } \\
& B_{z}=B_{y}=\frac{(9 / 70)+(3 / 10) \phi+(1 / 6) \phi^{2}-(6 / 5)(r / L)^{2}}{(1+\phi)^{2}} \text {, }
\end{aligned}
$$




$$
\begin{aligned}
& C_{z}=C_{y}=\frac{\left((11 / 210)+(11 / 120) \phi+(1 / 24) \phi^{2}+((1 / 10)-(1 / 2) \phi)(r / L)^{2}\right) L}{(1+\phi)^{2}}, \\
& D_{z}=D_{y}=\frac{\left((13 / 420)+(3 / 40) \phi+(1 / 24) \phi^{2}-((1 / 10)-(1 / 2) \phi)(r / L)^{2}\right) L}{(1+\phi)^{2}}, \\
& E_{z}=E_{y}=\frac{\left((1 / 105)+(1 / 60) \phi+(1 / 120) \phi^{2}+\left((2 / 15)+(1 / 6) \phi+(1 / 3) \phi^{2}\right)(r / L)^{2}\right) L^{2}}{(1+\phi)^{2}}, \\
& F_{z}=F_{y}=\frac{\left((1 / 140)+(1 / 60) \phi+(1 / 120) \phi^{2}+\left((1 / 30)+(1 / 6) \phi-(1 / 6) \phi^{2}\right)(r / L)^{2}\right) L^{2}}{(1+\phi)^{2}} .
\end{aligned}
$$

in which $r=\sqrt{I / A}$ and $\rho, A, L, I$, and $J$ are the density, cross section area, length, the diameter moment, and polar moment of inertia, respectively. $E$ and $G$ are Young's modulus and shear modulus, and $\Omega$ presents the rotating speed of the element.

The disc, described in the model as a lumped mass with 6 degrees of freedom is considered a concentrated mass located at the $i$ th node, as shown in Figure 4.

The mass node $i$ has 6 degrees of freedom and is defined as follows:

$$
\mathbf{u}_{\mathbf{d}}=\left\{\begin{array}{llllll}
x_{i} & y_{i} & z_{i} & \theta_{x i} & \theta_{y i} & \theta_{z i}
\end{array}\right\}^{T} .
$$

Its dynamic equation can be described as

$$
\mathbf{M}_{\mathbf{d}} \ddot{u}_{\mathbf{d}}=\mathbf{F}_{\mathbf{d}} \text {, }
$$

where $\boldsymbol{M}_{\mathrm{d}}=\operatorname{diag}\{m m m J p J d J d\}$ is the mass matrix, $m, J p$, and $J d$ are the mass, the equivalent mass $(\mathrm{Kg})$, polar moment of inertia $\left(\mathrm{Kg} \mathrm{m}^{2}\right)$, and diameter moment of inertia $\left(\mathrm{Kg} \mathrm{m}^{2}\right)$ for the disc. $\boldsymbol{F}_{d}$ is the force vector of mass element.

The spring-damper element for the support structure adopted in the FE model acting on the supported node is as shown in Figure 5.

The supported node $i$ has 6 degrees of freedom and is defined as follows:

$$
\mathbf{u}_{\mathbf{i}}=\left[\begin{array}{llllll}
x_{i} & y_{i} & z_{i} & \theta_{x i} & \theta_{y i} & \theta_{z i}
\end{array}\right]^{T},
$$

where, $x, y$, and $z$ are the corresponding displacements along the three local coordinate axes of node $i ; \theta_{x}, \theta_{y}$, and $\theta_{z}$ are the corresponding rotation angles around the three coordinate axes. The dynamic equation of the spring-damper element can be described as

$$
\mathbf{C}_{s} \dot{u}_{i}+\mathbf{K}_{s} \mathbf{u}_{i}=\mathbf{F}_{s} \text {, }
$$

where $\mathbf{F}_{s}$ is the force vector of the supporting element including an external additional load; $\mathbf{C}_{s}$ and $\mathbf{K}_{s}$ are the damping matrix and stiffness matrix of the supporting element, respectively. $C_{s}$ can be defined as proportional damping and described as $\mathbf{C}_{s}=\beta_{s} \cdot \mathbf{K}_{\mathbf{s}}$, where $\beta_{s}$ is the linear proportional coefficient, in the order of $1 \times 10^{-5} \sim 1 \times 10^{-3}$.
When the supports are identical and symmetrical ignoring the axial and angular stiffness, $\mathbf{K}_{s}=\operatorname{diag}\left\{\begin{array}{lllll}0 & k & k & 0 & 0\end{array}\right\}$. The radial stiffness of the support structures can be ascribed to the bearings, squirrel cages, bearing, and support houses and can be expressed as

$$
k=\frac{1}{\left(1 / k_{b}\right)+\left(1 / k_{c}\right)+\left(1 / k_{h}\right)},
$$

where $k_{c}, k_{b}$, and $k_{h}$ are the stiffness of the squirrel cage, bearing, and its houses, respectively (unit, $N / m$ ). Because of the stiffness of the squirrel cage (the order of magnitude about $1 \times 10^{6}$ ) far less than that of the bearing and its houses (the order of magnitude about $1 \times 10^{8}$ ), the stiffness of supports mainly depends on the squirrel cage. $k_{c}$ depends on the structural and material parameters, the value of which can be obtained as follows [25]:

$$
k_{c}=\frac{n E b h\left(b^{2}+h^{2}\right)}{2 l^{3}},
$$

where $k_{c}$ is the transverse stiffness of the squirrel cage $(\mathrm{N} / \mathrm{m})$, $n, l, b$, and $h$ are the number, length, cross-sectional width, and height of the squirrel cage rib, and $E$ is the elasticity modulus of the squirrel cage material. The stiffness of the supporting structure of the test rig can be evaluated about $4.84 \times 10^{6} \mathrm{~N} / \mathrm{m}$ by equation (13).

2.2.2. Strain Energy Distribution Analysis. For strain energy distribution analysis of the rotor system with flexible supports, equation (1) for free whirling can be rewritten as

$$
\mathbf{M} \ddot{q}+(\Omega \mathbf{G}+\mathbf{C}) \dot{q}+\mathbf{K q}=0
$$

The abovementioned $n \times n$ order equations $(n=66)$ can be extended to $2 n \times 2 n$ equations to solve the eigenproblem,

$$
\tilde{M} \dot{U}+\widetilde{K} \mathbf{U}=0
$$

where 

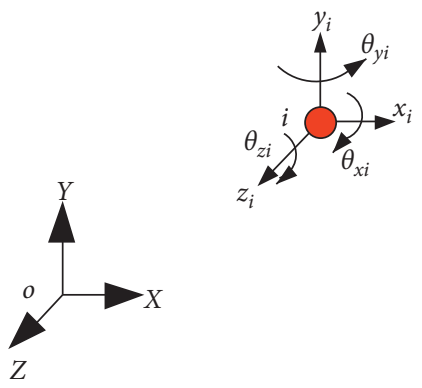

Figure 4: Lumped mass element for the disc.

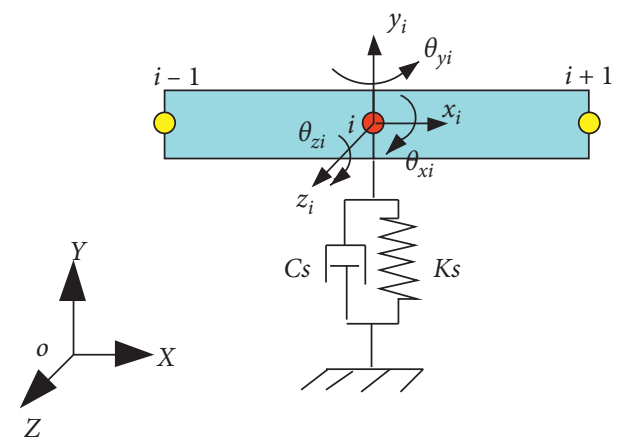

FIgURE 5: Spring-damper element for supporting.

$$
\begin{aligned}
\widetilde{M} & =\left[\begin{array}{cc}
\mathbf{M}_{n \times n} & 0_{n \times n} \\
0_{n \times n} & \mathbf{M}_{n \times n}
\end{array}\right]_{2 n \times 2 n}, \\
\widetilde{K} & =\left[\begin{array}{cc}
(\Omega \mathbf{G}+\mathbf{C})_{n \times n} & \mathbf{K}_{n \times n} \\
-\mathbf{M}_{n \times n} & 0_{n \times n}
\end{array}\right]_{2 n \times 2 n}, \\
\mathbf{U} & =\left[\begin{array}{cc}
\dot{q} & \mathbf{q}
\end{array}\right]_{1 \times 2 n}^{T} .
\end{aligned}
$$

The general solution $\mathbf{U}$ of equation (15) is then

$$
\mathbf{U}=\boldsymbol{\Phi} e^{\bar{\omega} t}
$$

where both the amplitude $\Phi$ and the frequency $\bar{\omega}$ are complex numbers. By introducing the solution into equation (15), the following characteristic equation is obtained:

$$
\left(\widetilde{K}+\bar{\omega}_{j} \tilde{M}\right) \Phi_{j}=0, \quad(j=1 \text { to } 2 n)
$$

Equation (18) is an ordinary differential equation, and its general eigenvalue problem can be changed into the issue of the coefficient matrices $-\widetilde{M}^{-1} \widetilde{K}$.

If considering the gyration and damping effects, the eigenvalues $\bar{\omega}_{j}$ and eigenvectors $\Phi_{j}(j=1$ to $2 n)$ can be expressed as

$$
\begin{array}{ll}
\bar{\omega}_{2 k}=\bar{\omega}_{k R} \pm \bar{i}_{k I}, & (k=1 \text { to } n), \\
\Phi_{2 k-1}^{2 k-1}=\varphi_{k R} \pm \bar{i} \varphi_{k I}, & (k=1 \text { to } n),
\end{array}
$$

where $\bar{i}=\sqrt{-1}$, the imaginary part of the eigenvalue, $\omega_{k \mathrm{I}}$ denotes the $k$ th order natural frequency, and the real part of the eigenvalue $\omega_{k \mathrm{R}}$ is related to the free whirl damping.
Correspondingly, the imaginary part of the eigenvector $\varphi_{k R}$ denotes the $k$ th order mode vector.

Introducing the modal energy distribution coefficient of supports for the $k$ th mode as the ratio $\eta$, it is expressed as

$$
\eta=\frac{\sum_{j}^{2} \varphi_{k R}^{T} \mathbf{K}_{s j} \varphi_{k R}}{\varphi_{k R}^{T} \mathbf{K} \varphi_{k R}} \times 100 \%, \quad(k=1 \text { to } n),
$$

where $\mathbf{K}_{s i}$ is the stiffness matrix of the $j$ th support. The numerator in formula denotes the potential energy of the $k$ th mode stored in supports, and the denominator in formula denotes the whole strain energy of the rotor system.

The values of $\eta$ are between 0 and 1 . It tends to 0 in the case of ideal stiff supports, to increase with increasing support flexibility, up to 1 in the case of ideal rigid rotor with flexible supports. As to the test rig, its first two modes and their corresponding energy distribution coefficients are shown in Figure 6. It is clearly seen that the shaft does not bend very much in the lower two modes, i.e., the first two modes of the system are referred to rigid-body modes and the strain energy approximately exists in the supports.

2.3. Rigid-Flexible Coupling Model of the System with Misalignment. According to the abovementioned investigations, the strain energy is mainly distributed on the squirrel cage supports. So, the squirrel cages should be accurately modeled. In this section, considering the flexibilities of squirrel cage supports, a rigid-flexible coupling dynamic model of the abovementioned system is established through a data exchange between ADAMS and ANSYS, in which the shaft and disc are built as rigid bodies and the squirrel cage is modeled as flexible body, as shown in Figure 7(a).

The two flexible bodies of the squirrel cages modeled by solid186 consisting of 5955 elements and 13569 nodes in MNF format from ANSYS are introduced in the ADAMS model on the locations of two supports, in which freedoms on the connection surface are coupled into one node in the center to simulate the whole movement of combined surfaces. By combining the shaft and the squirrel cage, two "Bushing" elements are adopted to replace the bearings in reality with the stiffness and damping coefficients of $1 \mathrm{e} 8 \mathrm{~N} / \mathrm{m}$ and $1 \mathrm{e} 5 \mathrm{~N} \mathrm{~m} / \mathrm{s}$, respectively, and the stiffness of bearing can be calculated by the classical calculation formula. Fixed joint between the squirrel cage and the "Ground" part is applied to simulate the connection between the squirrel cage and the support house.

The unbalance can be easily set by adding a rigid ball on the disc with certain mass and certain distance from the geometrical center of the disc. The misalignment condition can be obtained by relocating supporting positions upward with certain offset from the original positions. The misaligned model with an offset of $h$ on the right support is shown in Figure 7(b).

2.4. Model Validation. For model validation, the experimental modal test is carried out by the multihammering method on the four measurement points on the rigid shaft 


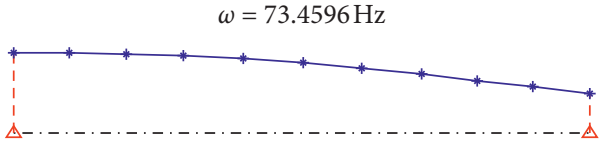

(a)

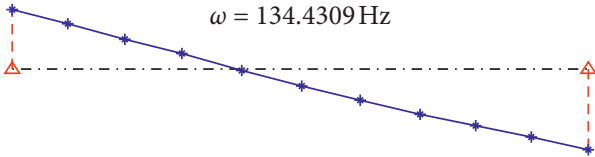

(b)

Figure 6: The first two modes and corresponding energy distribution coefficient $\eta$. (a) $1^{\text {st }}$ mode $\eta=88.82 \%$. (b) $2^{\text {nd }} \eta=92.49 \%$.

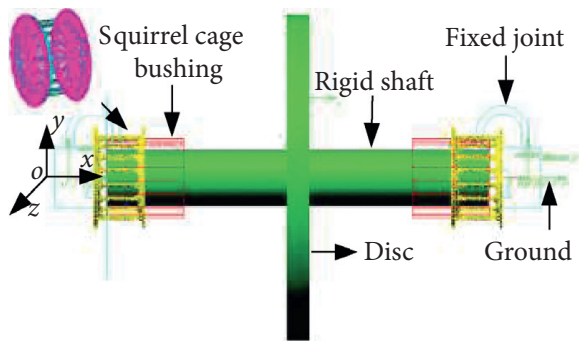

(a)

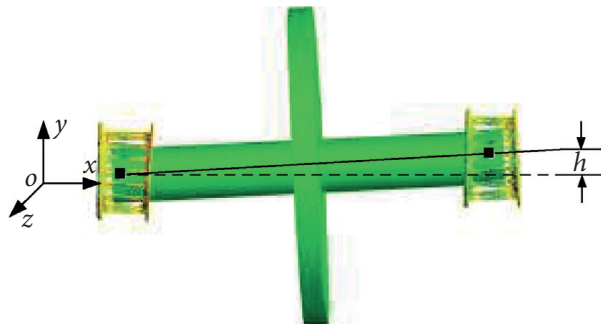

(b)

FIgURE 7: Rigid-flexible coupling model. (a) Normal condition. (b) Misaligned condition.

shown in Figure 1. By analyzing the modal stabilization diagram based on the measured data of LMS testlab shown in Figure 8, the first two natural frequencies can be clearly confirmed, i.e., $73.69 \mathrm{~Hz}$ and $115.68 \mathrm{~Hz}$.

By comparing the simulated results exhibited in Figure 9 with the measured results, the first two natural frequencies of the rigid-flexible coupling model are approximate to the tests, the different ratios for which are all within $4 \%$. The results demonstrate that the proposed rigid-flexible coupling model is reasonable, which can be adopted in the following analysis.

\section{Dynamic Characteristics of the Misaligned Rotor System}

Vibrations of the misaligned rigid rotor system and the stress of its support structures under different misalignment are investigated based on the established rigid-flexible coupling dynamic model with the measurements on the scaled test rig. The unbalance value of $50 \mathrm{~g} \mathrm{~cm}$ is adopted, which is verified by measured results [18].

Prior to the experimental analysis, the test rig must be aligned firstly. Based on the aligned condition, the scaled test rig is purposely misaligned vertically by adding several shims with a thickness of $1 \mathrm{~mm}$ under the support 2, and the rotating speeds are $65 \mathrm{~Hz}$ and $85 \mathrm{~Hz}$ in subcritical and supercritical ranges, respectively. A total of six test runs have been made, as shown in Table 4.

The operating conditions of the simulation analysis are similar to that of measurement as follows: the misalignment offsets range from 0 to $2 \mathrm{~mm}$ with an increment of $0.1 \mathrm{~mm}$.

3.1. Dynamic Behavior of the Misaligned Rotor System. With the misalignment values varying from $0 \mathrm{~mm}$ to $2 \mathrm{~mm}$, the radial vibrations of the misaligned rotor are analyzed. The vibration responses, the frequency spectrum, and orbits of experimental and simulated results with different misalignments at a rotating speed of $65 \mathrm{~Hz}$ are illustrated in Tables 5-7.

By comparing the responses with the misalignment offset values varying from $0 \mathrm{~mm}$ to $2 \mathrm{~mm}$ in Tables $5-7$, it is evident that the simulation results are similar to the tests. The peak response, the frequency component, and even the orbit are almost without obvious changes along the misalignment values. For further studies, the vibration amplitudes, i.e., half of the peak-to-peak values, are collected for comparisons between the simulation and measurement results under various misalignment conditions, as shown in Table 8.

As the misalignment increases, the vibration displacement amplitudes in the $z$-direction show very little change across each of the runs. It is noticed that the simulated results agree very well with the measurements. So, it is concluded that the misalignment condition has very little obvious effect on the vibrations of the rotor system, as exhibited in Tables $5-8$.

3.2. Stress Analysis of the Squirrel Cage. The strain gauges are stuck on the squirrel cage of support 2 to measure its stain in different operation conditions, as shown in Figure 10(a). Multiplying the measured stain by the elastic modulus listed in Table 3, the stress on the tested point of the squirrel cage can be easily obtained. The 4945\# node of the cage model of support 2 is corresponding to the tested point in measurement, shown in Figure 10(b).

Under the operating conditions shown in Table 4, the experiments and simulations are carried out, and the simulated results of the point are compared with the measurements as shown in Tables 9-11 at a rotating speed of $65 \mathrm{~Hz}$.

The simulation results approximate to the measured results when the misalignment offset values vary from $0 \mathrm{~mm}$ to $2 \mathrm{~mm}$, as shown in Figures $8-10$. Also, it is clearly seen 


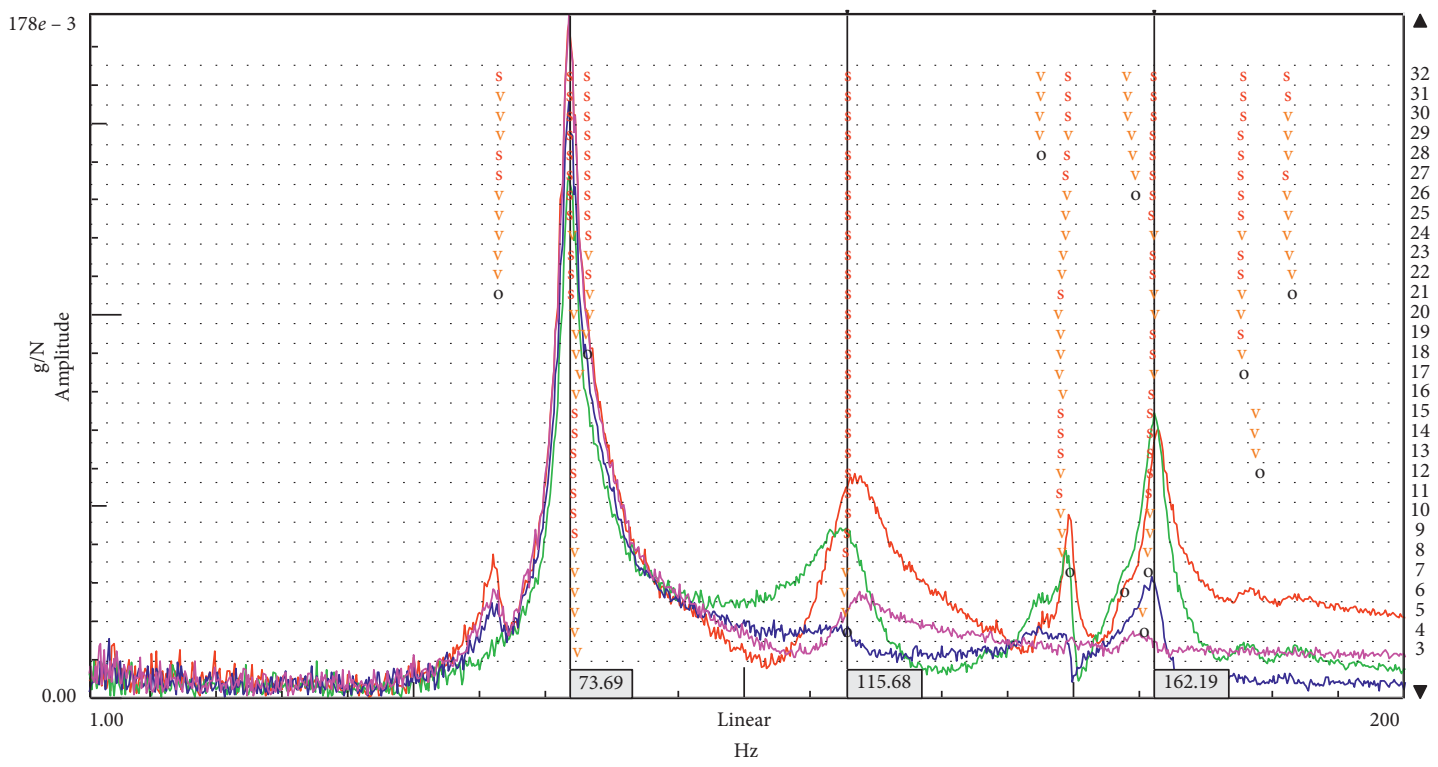

FIGURE 8: Modal stabilization diagram of the test rig.

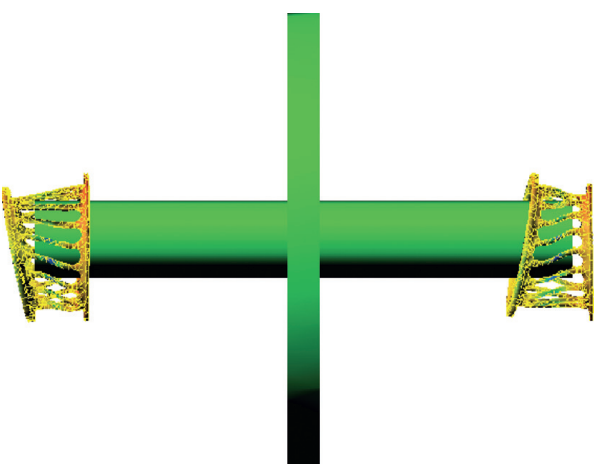

(a)

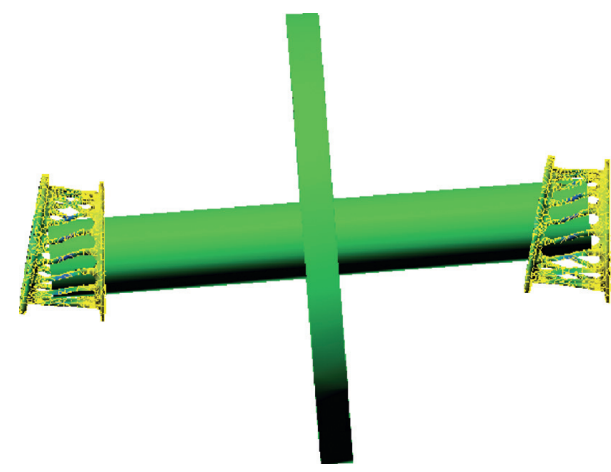

(b)

Figure 9: First two order natural frequencies and modes of the rotor system. (a) The $1^{\text {st }}$ order $(76.3 \mathrm{~Hz})$. (b) The $2^{\text {nd }}$ order $(116.43 \mathrm{~Hz})$.

TABLE 4: Operating conditions.

\begin{tabular}{lcc}
\hline Cases & Misalignment conditions & Rotating speeds \\
\hline Case 1 & Normal condition $(h=0 \mathrm{~mm})$ & $65 \mathrm{~Hz}, 85 \mathrm{~Hz}$ \\
Case 2 & One shim under support $2(h=1 \mathrm{~mm})$ & $65 \mathrm{~Hz}, 85 \mathrm{~Hz}$ \\
Case 3 & Two shims under support 2 $(h=2 \mathrm{~mm})$ & $65 \mathrm{~Hz}, 85 \mathrm{~Hz}$ \\
\hline
\end{tabular}

TABLE 5: Comparison of the vibration responses under normal condition $(h=0 \mathrm{~mm})$.

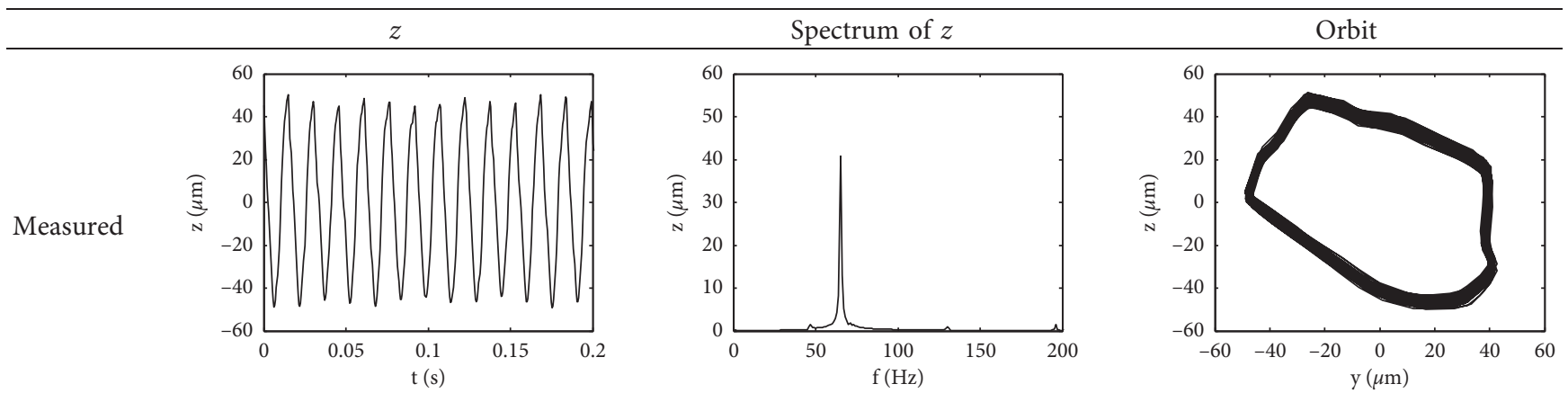


Table 5: Continued.

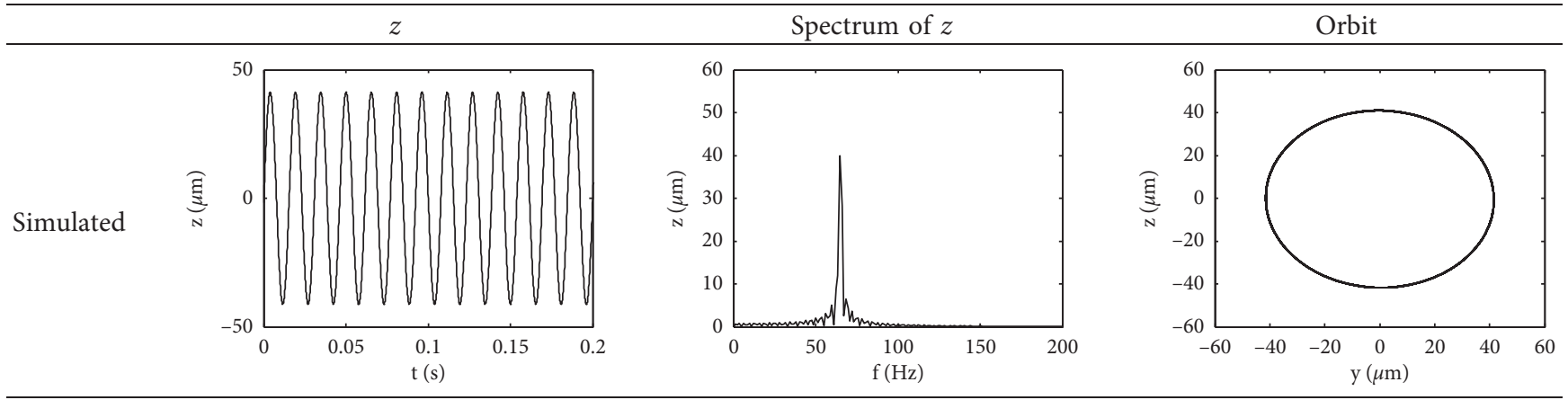

TABle 6: Comparison of the vibration responses under support 2 upward $1 \mathrm{~mm}$ condition $(h=1 \mathrm{~mm})$.
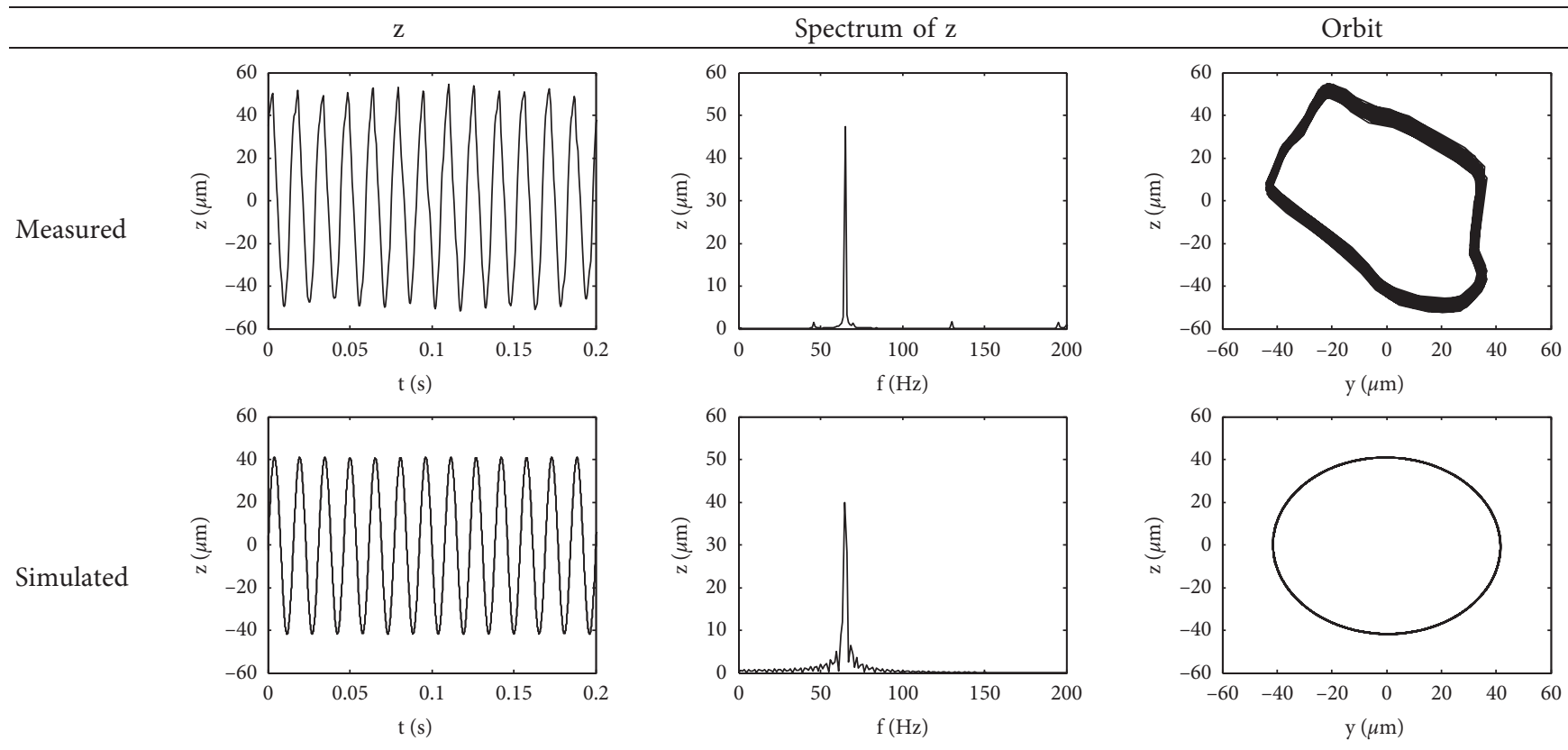

TABLE 7: Comparison of the vibration responses under support 2 upward $2 \mathrm{~mm}$ condition $(h=2 \mathrm{~mm})$.
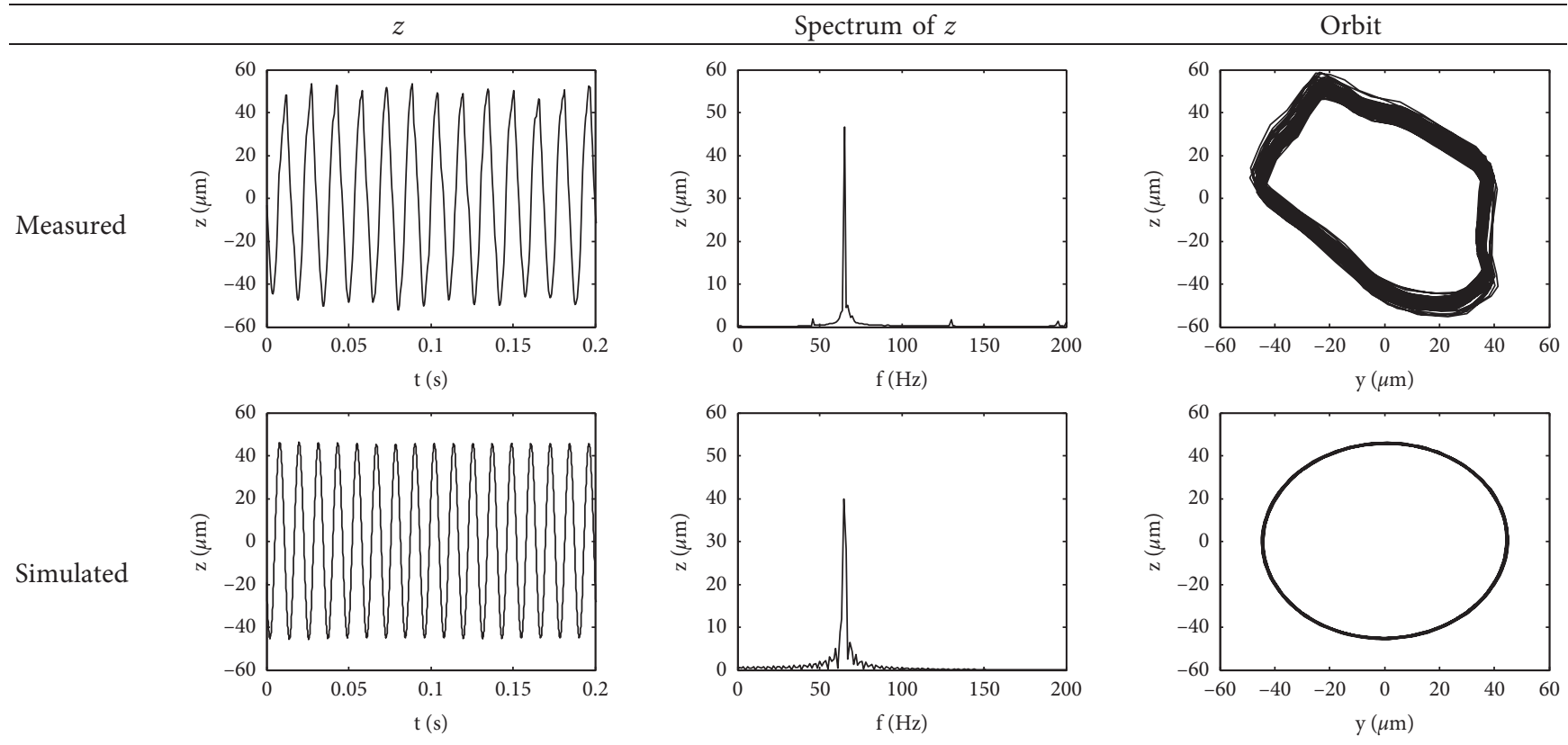
TABLE 8: Comparison of the vibration amplitudes for the measured and simulated results; unit: $\mu \mathrm{m}$.

\begin{tabular}{lcccc}
\hline Rotating speed $(\mathrm{Hz})$ & & $h=0 \mathrm{~mm}$ & $h=1 \mathrm{~mm}$ & \\
\hline \multirow{2}{*}{65} & Measurement & 44.99 & 44.36 & $4 \mathrm{~mm}$ \\
& Simulation & 42.91 & 42.17 & 45.01 \\
\multirow{2}{*}{85} & Measurement & 45.7 & 45.83 & 42.21 \\
\hline
\end{tabular}

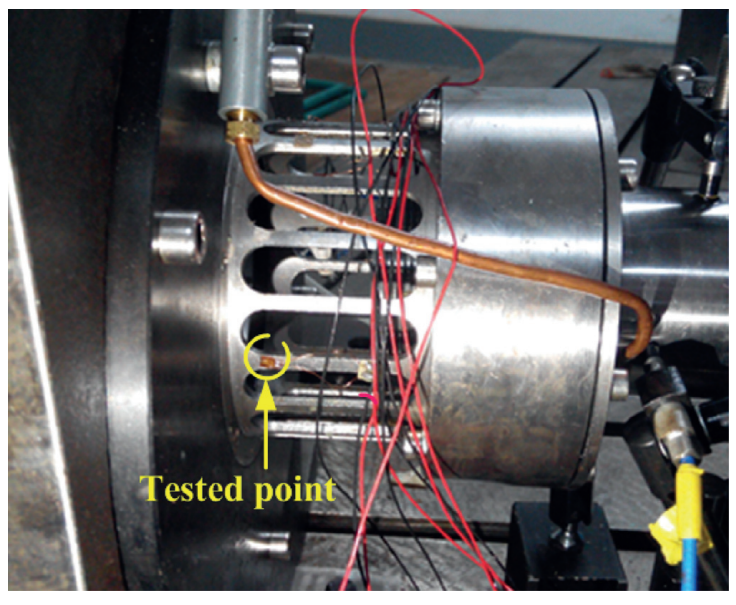

(a)

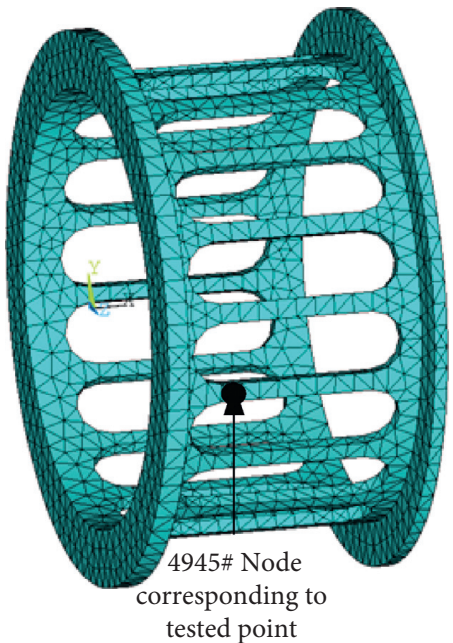

(b)

Figure 10: Tested point of stress on the squirrel cage. (a) Tested point. (b) Corresponding tested point in the model.

TABle 9: Comparison of stress on the squirrel cage under normal condition $(h=0 \mathrm{~mm})$.

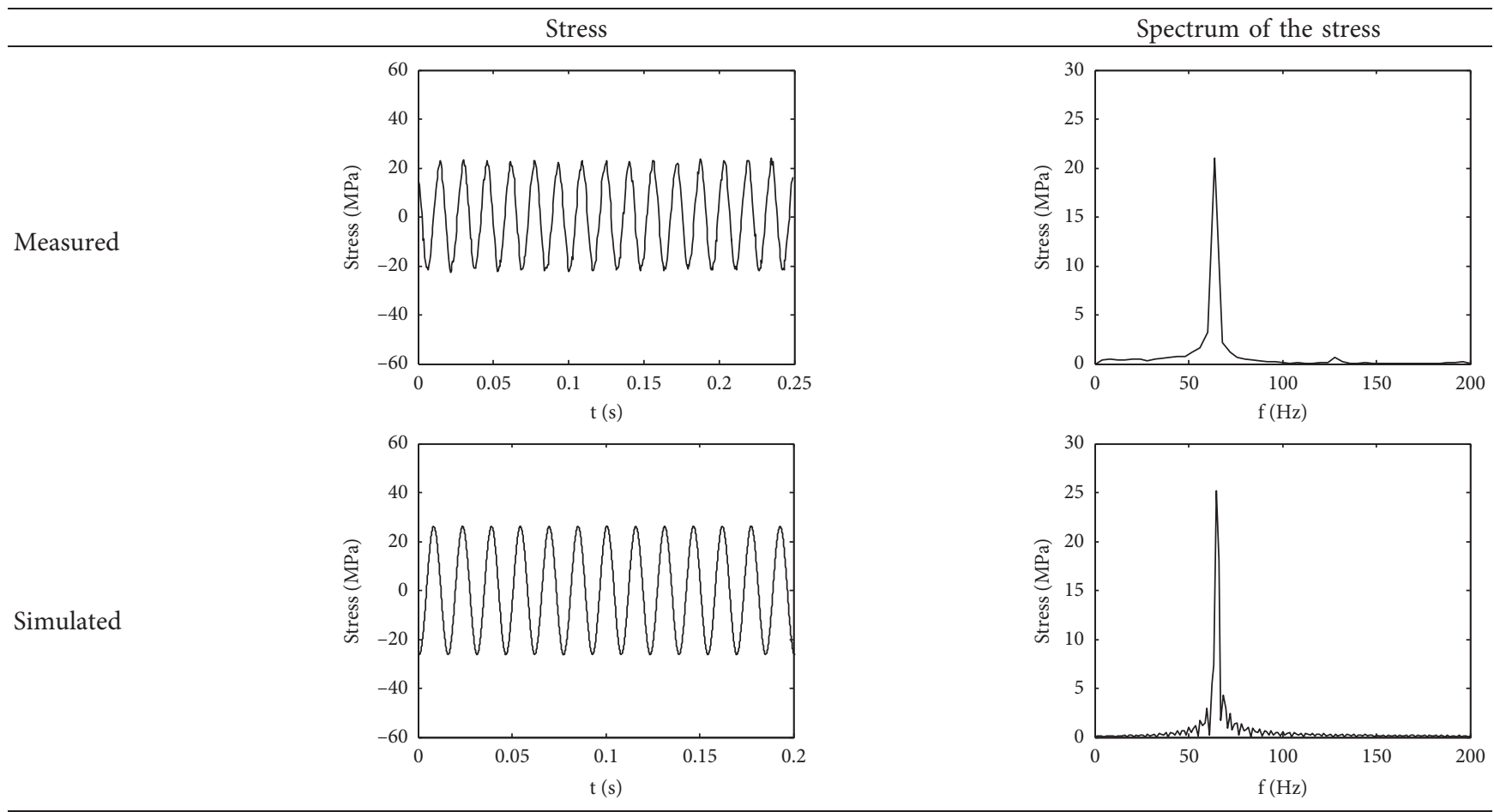

that the static stress (i.e., the mean value of stress) of the tested point on the squirrel cage greatly increases along with the misalignment values. However, the stress amplitudes (peak values of the stress) did not show significant differences under different misaligned conditions. 
TABLE 10: Comparison of stress on the squirrel cage under support 2 upward $1 \mathrm{~mm}(h=1 \mathrm{~mm})$.

Measured

TABLE 11: Comparison of stress on the squirrel cage under support 2 upward $2 \mathrm{~mm}(h=2 \mathrm{~mm})$.

Measured

Comparisons under the operating conditions have been made quantitatively, as shown in Figure 11, in which $S_{A m}$ and $S_{A m}$ (measurement) denote simulated and measured stress amplitudes of the squirrel cage in the same test point and $S_{A v}$ and $S_{A v}$ (measurement) denote simulated and measured static stress results. It is worth noting that the static stress of the squirrel cage increases just about proportionally with the amount of misalignment, and the stress 


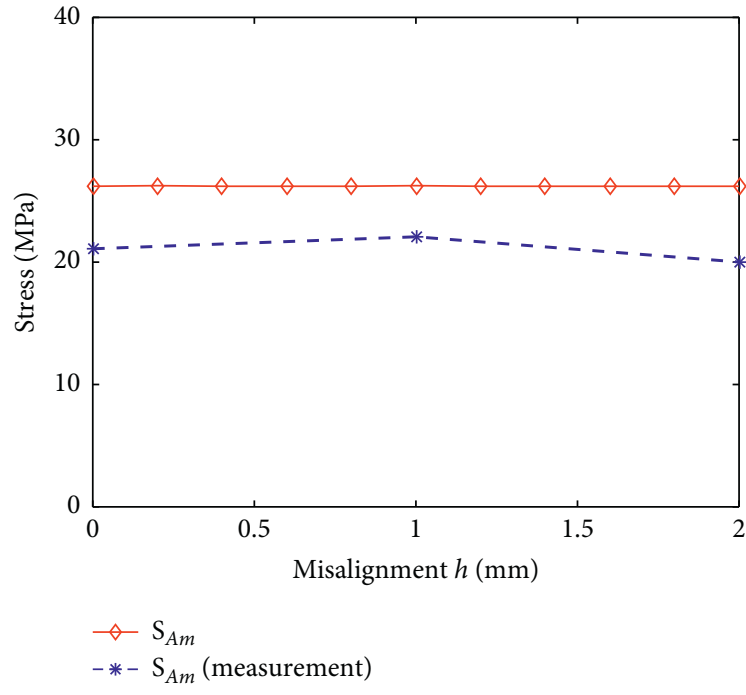

(a)

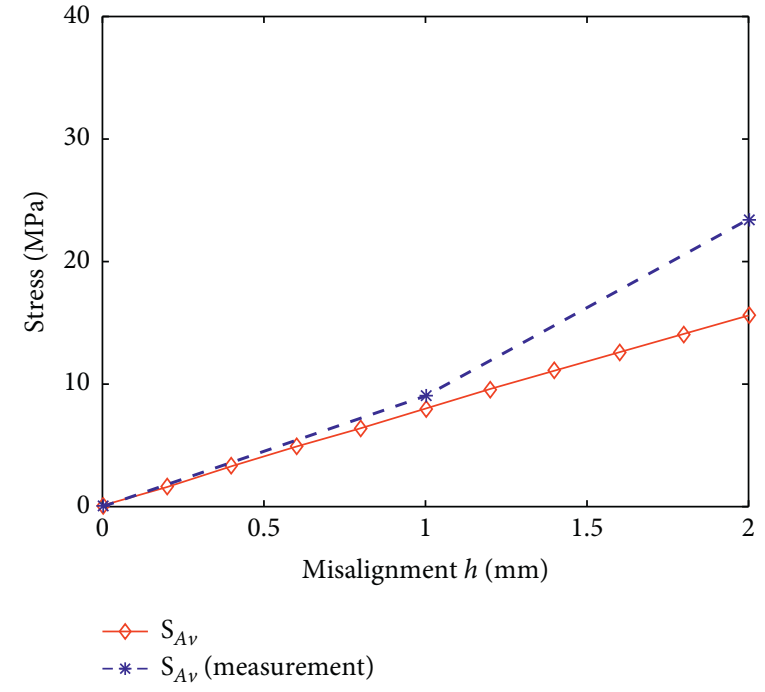

(b)

Figure 11: Comparison of the stress amplitudes and static stress for the measured and simulated results. (a) Comparison of the stress amplitudes. (b) Comparison of static stress.

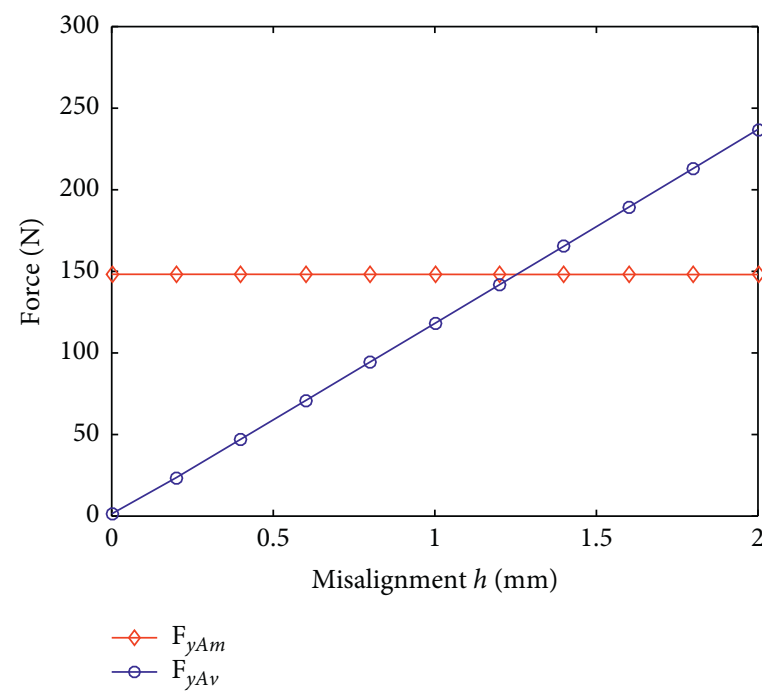

(a)

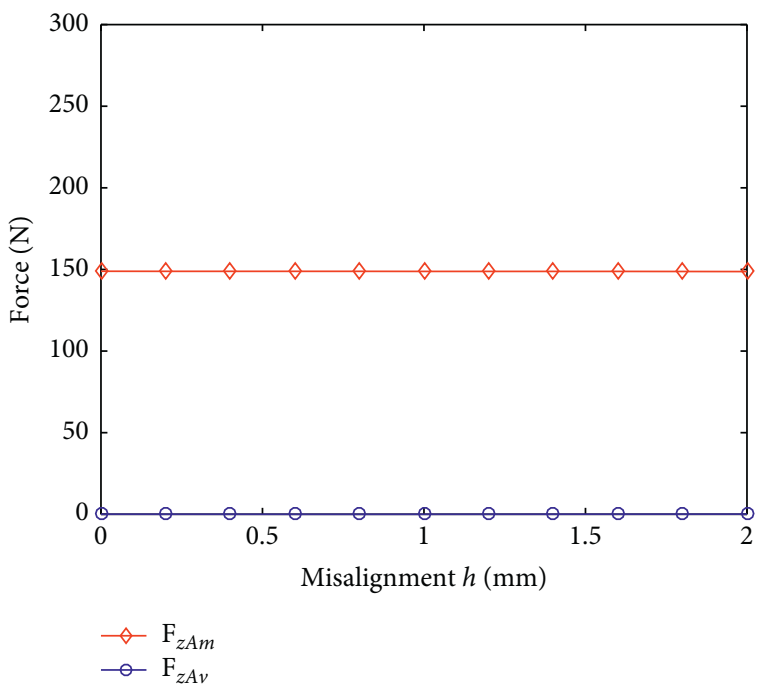

(b)

FIGURE 12: Reaction forces characteristic of misaligned support. (a) Forces in the $y$-direction (misalignment direction). (b) Forces in the $z$-direction.

amplitudes drawn show very little change across each of the runs. The more serious the misaligned condition, the higher the static stress of the squirrel cage.

Misalignment conditions bring out the additional reaction forces in misaligned condition directly, as shown in Figure $12\left(F_{y A m}, F_{y A v}\right.$ denote the amplitude and static of the reaction forces in the $y$-direction, and $F_{z A m}, F_{z A v}$ denote the amplitude and static of the reaction forces in the $z$-direction), and the reaction forces in the $y$-direction (misaligned direction) increases. The amplitudes of reaction forces almost remain unchanged, which mainly result from the same rotor unbalance level. However, the static of the reaction forces in the misaligned direction proportionally with the amount of misalignment is as shown in Figure 11, which will bring out higher stress and even more serious damage risk for the flexible supports than other parts in the rigid rotor system due to the misalignment.

\section{Conclusions}

In this paper, a rigid-flexible coupling dynamic model is established through a data exchange between ADAMS and ANSYS according to the strain energy distribution analysis by the finite element method, considering the flexibility of the supports and misaligned conditions, and also validated by measurements. Then, vibrations of the rotor and the 
stress of its support structures under different misalignments are investigated analytically and experimentally.

Both the simulated and measured results reveal that the misalignment almost has no obvious effect on the vibrations of the rotor system and the stress amplitudes of the squirrel cage, but greatly influences its static stress. As the misalignment increases, the vibration displacement amplitudes expressed in the peak values show very little change across all the misalignment conditions. The static stress of the squirrel cage increases just proportionally with misalignment levels, but the stress amplitudes drawn show very little change. The more serious the misaligned condition, the higher the static stress of the squirrel cage. Because misalignment brings out the additional reaction forces in the misaligned direction, it will further result in higher stress and even more serious damage risk for the flexible supports than other parts in the rigid rotor system.

\section{Data Availability}

The underlying data can be obtained from the corresponding author on request.

\section{Conflicts of Interest}

The authors declare that there are no conflicts of interest.

\section{Acknowledgments}

This work was financially supported by the National Natural Science Foundation of China (Grant No. 51905069), the Natural Science Foundation and "Xingliao Talent Program" Project of Liaoning Province (Grant Nos. 2019-ZD-0088 and XLYC1807112), and the Innovation Training Programme Foundation for the High-Level Talents by Dalian of Liaoning Province (Grant No. 2018RQ50).

\section{References}

[1] J. Piotrowski, Shaft Alignment Handbook, Marcel Dekker, New York, NY, USA, 3 edition, 2007.

[2] G. Genta, Dynamics of Rotating Systems, Springer, Berlin, Germany, 2005.

[3] O. Civalek, B. Uzun, M. O. Yaylı, and B. Akgöz, "Size-dependent transverse and longitudinal vibrations of embedded carbon and silica carbide nanotubes by nonlocal finite element method," The European Physical Journal Plus, vol. 135, no. 4, p. 381, 2020.

[4] B. Akgöz and Ö. Civalek, "Longitudinal vibration analysis for microbars based on strain gradient elasticity theory," Journal of Vibration and Control, vol. 20, no. 4, pp. 606-616, 2014.

[5] G. Chen, "Vibration modelling and verifications for whole aero-engine," Journal of Sound and Vibration, vol. 349, pp. 163-176, 2015.

[6] Y. Zuo and J. Wang, "A component mode synthesis method for 3-D finite element models of aero-engines," Journal of Mechanical Science and Technology, vol. 29, no. 12, pp. 5157-5166, 2015.

[7] M. Xu and R. D. Marangoni, "Vibration analysis of a motor-flexible coupling-rotor system subject to misalignment and unbalance, part I: theoretical model and analysis," Journal of Sound and Vibration, vol. 176, no. 5, pp. 663-679, 1994.
[8] M. Xu and R. D. Marangoni, "Vibration analysis of a motor-flexible coupling-rotor system subject to misalignment and unbalance, part II: experimental validation," Journal of Sound and Vibration, vol. 176, no. 5, pp. 681-691, 1994.

[9] A. S. Sekhar and B. S. Prabhu, "Effects of coupling misalignment on vibrations of rotating machinery," Journal of Sound and Vibration, vol. 185, no. 4, pp. 655-671, 1995.

[10] Y.-S. Lee and C.-W. Lee, "Modelling and vibration analysis of misaligned rotor-ball bearing systems," Journal of Sound and Vibration, vol. 224, no. 1, pp. 17-32, 1999.

[11] K. Hussain and I. Redmond, "Dynamic response of two rotors connected by rigid type mechanical coupling with parallel misalignment," Journal of Sound and Vibration, vol. 249, no. 3, pp. 483-498, 2002.

[12] I. Redmond, "Study of a misaligned flexibly coupled shaft system having nonlinear bearings and cyclic coupling stiffness-Theoretical model and analysis," Journal of Sound and Vibration, vol. 329, no. 6, pp. 700-720, 2010.

[13] P. Pennacchi, A. Vania, and S. Chatterton, "Nonlinear effects caused by coupling misalignment in rotors equipped with journal bearings," Mechanical Systems and Signal Processing, vol. 30, pp. 306-322, 2012.

[14] S. Feng, H. Geng, and L. Yu, "Rotordynamics analysis of a quill-shaft coupling-rotor-bearing system," Proceedings of the Institution of Mechanical Engineers, Part C: Journal of Mechanical Engineering Science, vol. 229, no. 8, pp. 1385-1398, 2015.

[15] J. Yi, B. Pang, H. Liu, F. Wang, B. Ji, and M. Jing, "Influence of misalignment on nonlinear dynamic characteristics for matched bearings-rotor system," Proceedings of the Institution of Mechanical Engineers, Part K: Journal of Multi-Body Dynamics, vol. 228, no. 2, pp. 172-181, 2014.

[16] K. T. Fu, D. P. Zheng, Y. X. Ou et al., The 19th Copy of Aircraft Engine Design Hand-Book-Rotor Dynamics and the Whole Machine Vibration, Aviation Industry Press, Beijing, China, 2000pp. 101-160, (in Chinese).

[17] S. J. MorandiChan and M. F. Liao, "Experimental investigation on rotor vibration control by using active elastics support/dry friction dampers," Journal of Aerospace Power, vol. 23, no. 11, pp. 2026-2030, 2008, (in Chinese).

[18] M. Wang, Q. Han, B. Wen et al., "Modal characteristics and unbalance responses of fan rotor system with flexible support structures in aero-engine," Proceedings of the Institution of Mechanical Engineers Part G: Journal of Aerospace Engineering, vol. 231, no. g9, pp. 1686-1705, 2017.

[19] T. Messager and M. Pyrz, "Discrete optimization of rigid rotor balancing," Journal of Mechanical Science and Technology, vol. 27, no. 8, pp. 2231-2236, 2013.

[20] J. Zapoměl, P. Ferfecki, and P. Forte, "A computational investigation of the steady state vibrations of unbalanced flexibly supported rigid rotors damped by short magnetorheological squeeze film dampers," Journal of Vibration and Acoustics, vol. 135, no. 6, Article ID 064505, 2013.

[21] J. Liu, "A dynamic modelling method of a rotor-roller bearing-housing system with a localized fault including the additional excitation zone," Journal of Sound and Vibration, vol. 469, p. 115144, 2020.

[22] J. Liu and Y. Shao, "Dynamic modeling for rigid rotor bearing systems with a localized defect considering additional deformations at the sharp edges," Journal of Sound and Vibration, vol. 398, no. Complete, pp. 84-102, 2017. 
[23] A. Bekir and C. Ömer, "Bending analysis of embedded carbon nanotubes resting on an elastic foundation using strain gradient theory," Acta Astronautica, vol. 119, pp. 1-12, 2016.

[24] Z. Luo, Y. Zhu, Q. Han et al., "The dynamic similitude design of a thin-wall cylindrical shell with sealing teeth and its geometrically distorted model," Advances in Mechanical Engineering, vol. 7, no. 2, pp. 1-12, 2015.

[25] G. Feng and B. Zhou, "Optimization design and test investigation of squirrel cage elastic support," Journal of Aerospace Power, vol. 26, no. 1, pp. 199-203, 2011. 